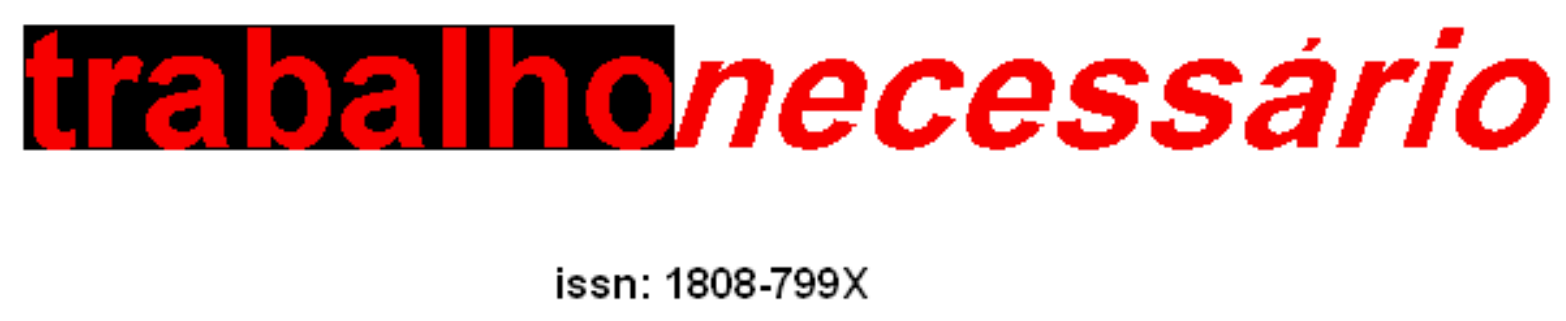

ano 4 - número 4 - 2006

\title{
A (DE) FORMAÇÃO HUMANA E O MUNDO DO TRABALHO: A PRODUÇÃO DE SUBJETIVIDADES FLEXÍVEIS EM TEMPOS DE ACUMULAÇÃO FLEXÍVEL DO CAPITAL*
}

Maria Emília Pereira da Silva**

\section{Introdução}

A flexibilidade surge como a grande mudança na estética do capitalismo atual. Diz-se que vivemos num capitalismo "flexível". O conhecido "sistema capitalista", de "livre empresa" ou "iniciativa privada", adquiriu essa nova qualidade. Agregada à idéia de liberdade, a flexibilidade que o caracteriza vem acompanhada do combate à rigidez da burocracia e da apologia ao risco, levando a crer que agora todos estão mais livres para organizar seu trabalho, sua vida. E assim é a rotina destituída do seu antigo status.

Espera-se que os trabalhadores sejam mais ágeis, abertos a mudanças no processo de trabalho e predispostos a assumir riscos, sem aquela cega obediência a leis e procedimentos formais da época do fordismo. Entretanto, sem a visibilidade das antigas regras, os novos controles dificultam seu entendimento, sobretudo, em relação a aspectos de subjetividade, como entender o modo pelo qual a flexibilidade age sobre o caráter[1]. Contudo, mais difícil se tornará entender como se produzem as novas subjetividades, sem um détour que leve à compreensão de como se configurou o capitalismo na sua atual fase flexível. É evidente a imensa mudança com que se dá a conhecer aos nossos olhos, mas trata-se de uma mudança aparente em sua forma. A lógica inerente da acumulação capitalista e das suas tendências de crise parece inalterada. Com efeito, é preciso considerar que se trata de um sistema dado a metamorfoses a cada época, que não se apresentam abruptamente, mas através de momentos de transição, de crises materializadas em mudanças, que prenunciam um novo regime de acumulação. Esta é a lógica capitalista, e, ao que tudo parece, vem operando desde o final do século passado, sob a nova forma flexível.

É certo que a palavra flexibilidade tem uma história. Sua origem está, no século quinze, na simples observação de uma árvore, cujos galhos se dobram ao vento, mas não quebram, sempre retornam à posição inicial. Se visto nesse sentido, o comportamento humano 
flexível adquire a mesma elasticidade, podendo adaptar-se a situações diversas, sem deixar se abater. Será este o sentido que hoje impulsiona a sociedade a criar instituições mais flexíveis, a buscar se livrar dos males da rotina? Estariam as práticas de flexibilidade mais propícias a forças que envergam as pessoas? Os novos imperativos do capital estariam produzindo subjetividades resistentes ou submissas? Que alternativas haverá de sobrevivência e auto-realização face aos males da flexibilidade nesse contexto?

Houve um tempo em que a teoria sobre os sentimentos morais se baseava nos estímulos externos, variáveis, numa flexibilidade vinda de fora, que deixava o indivíduo ao sabor dos acontecimentos. Após esse momento, porém, relacionou-se esse tipo de flexibilidade a virtudes empresariais. Economistas políticos do século opuseram a agilidade do empresário à lerdeza do trabalhador industrial. O comportamento flexível era visto como gerador de liberdade pessoal. Hoje, a nova economia política vem se contrapor a essa expectativa. Mas, repudiando a rotina burocrática em busca da flexibilidade, produziram-se novas estruturas de poder e controle. Estruturas que estão longe de criar as condições para a emancipação do homem.

Analisar a flexibilidade implica, por outro lado, em examinar sua oponente: a rigidez. Termo expressivo, ao relacionar-se à incapacidade do fordismo e do keynesianismo em conter as inerentes contradições capitalistas. Dificuldades cada vez mais evidentes, quando os problemas de rigidez se apresentavam nos investimentos de capital em sistemas de produção em massa; nos mercados; na alocação e contratos de trabalho. A rigidez dos compromissos do Estado se intensificava à proporção que aumentavam os programas de assistência, como seguridade social, direitos de pensão etc., enquanto as finanças ficavam além dos recursos. Instala-se uma profunda crise fiscal e de legitimidade desse Estado intervencionista. A "onda inflacionária" que poria termo à expansão alcançada no pósguerra, tem início nesse momento, por meio de uma política monetária capaz de dar uma resposta flexível, que consistia em imprimir a quantidade de moeda necessária à estabilização da economia.

As oscilações e incertezas que caracterizaram a época da profunda recessão de 1973, agravada pelo impacto da crise do petróleo, fizeram das décadas de 1970 e 1980 um período de reestruturação econômica e de reajuste social e político. Criaram um espaço social propício a novas experiências no âmbito da organização industrial e da vida política e social. Talvez nessas experiências possamos encontrar os primeiros vestígios de um novo modo de acumulação, que traz no seu bojo um distinto sistema de regulamentação política e social.

\section{Flexibilidade: uma noção polissêmica}

Não há unanimidade em termos do que representa a flexibilidade no mundo atualmente. 
Uma síntese de Harvey (2005) mostra que se estão esboçando três posições amplas, que podem ajudar a entender os desdobramentos dessa noção na realidade concreta dos nossos dias.

A primeira posição vê as novas tecnologias abrindo a possibilidade de uma reconstituição das relações de trabalho e dos sistemas de produção em bases completamente distintas, no âmbito social, econômico e geográfico. Nessa concepção, estaríamos na presença de uma espécie de "segunda divisão industrial". As novas formas de organização do trabalho e os novos "princípios locacionais" estariam transformando radicalmente a face do capitalismo.

Uma série de fatos tem contribuído para a formação de um corrente de pensamento que vislumbra grande transformação no modo de operar do capitalismo no final do século XX. Fatos como, o retorno do interesse pelos pequenos negócios; a redescoberta do trabalho duro e não muito bem remunerado, como também de atividades informais de vária natureza; o reconhecimento do importante papel desempenhado por essas formas de trabalho no desenvolvimento econômico na contemporaneidade, até mesmo nos países altamente industrializados e a tentativa de delinear o "percurso das rápidas mudanças geográficas do emprego e das fortunas" (Harvey, 2005, p. 177).

Na segunda posição, a flexibilidade é considerada um termo "extremamente poderoso" que dá legitimidade a um conjunto de práticas políticas, sobretudo, reacionárias e contrárias ao trabalhador. Alega-se não haver nenhuma novidade na busca capitalista de maior flexibilidade ou vantagem geográfica e que são fracas ou insuficientes as provas objetivas de uma mudança radical na maneira de operar do capitalismo. Contestando essa visão, Harvey afirma serem demasiado claras as provas de uma crescente flexibilidade em todo o mundo capitalista, como a subcontratação, o emprego temporário, as atividades autônomas etc., admitindo, porém, que as críticas realizadas por essa posição introduzem algumas correções importantes no debate.

Para Harvey, é por certo correta, e, segundo o autor, uma leitura cuidadosa de O Capital de Marx lhe dá sustentação, a "insistência de que não há nada essencialmente novo no impulso para a flexibilidade e de que o capitalismo segue periodicamente esses tipos de caminhos". Também merece cuidadosa consideração, segundo esse autor, o argumento de que "há um agudo perigo de se exagerar a significação das tendências de aumento da flexibilidade e da mobilidade geográfica, deixando-nos cegos para a força que os sistemas fordistas de produção implantados ainda têm" (ibidem). As conseqüências ideológicas e políticas da superacentuação da flexibilidade, no sentido estrito de técnica de produção e de relações de trabalho, também são consideradas suficientemente sérias para nos levar a "sóbrias e cautelosas avaliações do grau do imperativo da flexibilidade".[2] 
Embora relevantes os argumentos em prol dessa posição, Harvey considera igualmente "perigoso" fazer de conta que nada mudou, quando a maioria dos trabalhadores assiste à realidade da desindustrialização e da transferência geográfica de fábricas, das práticas mais flexíveis de emprego do trabalho e da flexibilidade dos mercados de trabalho, da automação e da inovação de produtos.

A terceira é uma posição intermediária entre os dois extremos anteriores. Representa a idéia defendida por Harvey de uma transição do fordismo para a acumulação flexível. Segundo essa visão, as tecnologias e formas organizacionais flexíveis não se tornaram hegemônicas em toda parte, como também o fordismo que as precedeu não o foi. $O$ entendimento é o de que a atual conjuntura se caracteriza por uma combinação de produção fordista altamente eficiente, com recorrência a tecnologia e produto flexível, em alguns setores e regiões, e de sistemas de produção mais tradicionais que se apóiam em relações de trabalho "artesanais", paternalistas ou patriarcais (familiares) que se distinguem por diferentes mecanismos de controle do trabalho. Harvey avalia que estes últimos cresceram a partir de 1970, mesmo nos países capitalistas avançados e muitas vezes às custas da linha de produção da fábrica fordista, mudança que tem importantes implicações no âmbito do sistema de produção e apropriação de mais-valia, na natureza e composição da classe trabalhadora global e mesmo nas condições de formação de consciência e de ação política.[3]

Segundo Harvey, não é irreversível a "passagem para sistemas alternativos de controle do trabalho", com todas as implicações políticas que isso acarreta. Trata-se de uma resposta tradicional à crise, já que a desvalorização da força de trabalho sempre foi "a resposta instintiva dos capitalistas" à queda de lucros. Entretanto, alerta esse autor, a generalidade dessa afirmativa esconde alguns movimentos contraditórios. Se as novas tecnologias permitiram o aumento do poder de camadas privilegiadas, ao mesmo tempo possibilitaram a sistemas alternativos de produção e de controle do trabalho abrir caminho para a alta remuneração de habilidades técnicas, gerenciais e de caráter empreendedor. A tendência tem sido a de aumentar as desigualdades de renda, prenunciando o surgimento de uma nova aristocracia do trabalho e de uma subclasse mal-remunerada e desprovida de poder. Esse quadro, no ponto de vista do autor, traria sérios problemas quanto à sustentação da demanda efetiva e coloca no horizonte a possibilidade de uma crise de subconsumo, que, afinal, é a materialização do tipo de crise que o fordismo-keynesianismo pretendeu evitar. Por isso, Harvey não vê como solução de curto prazo para as tendências de crise do capitalismo o apelo a um "monetarismo neoconservador" que recorre a modos flexíveis de acumulação e à desvalorização geral da força de trabalho aumentando o controle do trabalho.

\subsection{Flexibilidade: revolta contra a rotina ou projeto de auto-realização humana?}


Se na sociedade moderna o tempo rotineiro, burocrático, é visto como ameaça que pode paralisar o trabalho, o governo e outras instituições, no início do capitalismo industrial não eram tão evidentes os malefícios da rotina. Segundo Sennett (1999, p. 35), em meados do século dezoito, parecia que o trabalho repetitivo apontava duas diferentes direções, "uma positiva e frutífera, outra destrutiva". O lado positivo foi descrito por Diderot, que acreditava poder a rotina no trabalho ser como qualquer outra forma de aprendizado por repetição, "um professor necessário" (idem). O lado negativo do tempo de trabalho regular foi representado "da forma mais dramática" por Adam Smith, para quem a rotina embrutece o espírito. Para Diderot, a repetição e o ritmo podiam levar o trabalhador a alcançar "a unidade mental e manual" no trabalho. Estava convicto de que, pelo trabalho, os seres humanos encontram a paz consigo mesmo; acreditava que a partir do momento em que dominam a rotina e seus ritmos, as pessoas ao mesmo tempo assumem o controle e se acalmam. Na visão de Smith (idem, p. 39), "essas imagens de ordeira evolução, fraternidade e serenidade representam um sonho impossível", pois na realidade "a rotina embrutece o espírito".

Hoje, a flexibilidade ganha espaço em detrimento da rotina. Se outrora o tempo rotinizado convertera-se numa conquista pessoal, agora é o tempo flexível que ganha status no mundo do trabalho e da vida em geral.

Teria a rotina esgotado seu papel face às demandas do capital? Nos setores dinâmicos da economia a rotina vem dando lugar à flexibilidade, entretanto, o fordismo ainda se faz majoritariamente presente em termos da força de trabalho. Estima-se que pelo menos dois terços dos trabalhos são repetitivos, sendo que o uso do computador no trabalho também envolve, na sua maioria, tarefas rotineiras (Sennett, idem). E então retornamos à discussão anterior: o trabalho rotineiro precisa ser necessariamente degradante? Por outro lado, experiências mais flexíveis realmente estimulam as pessoas no trabalho? Supondo que há um efeito pacificador da rotina sobre o caráter, parece central a questão suscitada por Sennett (idem), no sentido de saber como a flexibilidade vai exatamente fazer um "ser humano mais engajado".

Na concepção de Marx, somente se existir uma necessidade interior de trabalho é que este "poderá perder seu caráter de necessidade exterior ao homem" (Mészáros, 1981, p. 167). Entendia ser esta necessidade exterior uma atividade vital do homem, apenas, enquanto meio para atingir um fim, e não como uma "atividade livre" com um fim em si mesmo. Nesse sentido, o trabalho como auto-realização humana só é possível caso se torne para o homem uma necessidade interior.

Já que o trabalho só é gozo, como necessidade positiva, como necessidade interior, a auto-realização, a realização humana, é inseparável do aparecimento dessa necessidade positiva. A liberdade é, assim, a realização do objetivo do homem: a auto-realização no exercício autodeterminado e externamente não- 
impedido dos poderes humanos. Como autodeterminação, a base desse exercício livre dos poderes humanos não é um "imperativo categórico" abstrato, que permanece exterior ao ser humano real, mas uma necessidade positiva. Os meios

(trabalho) e fins (necessidade) nesse processo de humanização transformam-se mutuamente e criam uma atividade verdadeiramente humana, feita de gozo e auto-realização, pela qual o poder e a finalidade, os meios e fins, surgem numa unidade natural (humana) (Mészáros, 1981, p. 167).

Tal análise nos leva a refazer a questão nos termos de Marx: como pode a flexibilidade no mundo do trabalho contribuir para a transformação do homem num "rico ser humano", um ser auto-realizado? Esta discussão remete à questão central do debate - a resolução da contradição entre meios e fins, entre a necessidade e a liberdade, ou como dizia Engels, "a reconciliação da humanidade com a natureza e consigo mesma” (apud Mészáros, idem, p. 166)[4].

\section{Acumulação flexível: o combate à rigidez do fordismo}

A acumulação flexível, expressão cunhada por Harvey para designar o atual estágio capitalista, é assim denominada por marcar um confronto direto com a rigidez do fordismo. Segundo o autor, ela se apóia na flexibilidade dos processos de trabalho, dos mercados de trabalho, dos produtos e padrões de consumo. Poderíamos dizer que essa forma de acumulação caracteriza-se pela inovação: "surgimento de setores de produção inteiramente novos, novas maneiras de fornecimento de serviços financeiros, novos mercados e, sobretudo, taxas altamente intensificadas de inovação comercial, tecnológica e organizacional" (idem, p. 140). Ressalte-se que a acumulação flexível "envolve rápidas mudanças dos padrões do desenvolvimento desigual, tanto entre setores como entre regiões geográficas, criando, por exemplo, um vasto movimento no emprego no chamado 'setor de serviços', bem como conjuntos industriais completamente novos em regiões até então subdesenvolvidas" (ibidem). Envolve também um novo movimento que Harvey (idem) denomina de "compressão do espaço-tempo" no mundo capitalista, expressão com a qual pretende indicar que "os horizontes temporais da tomada de decisões privada e pública se estreitam, enquanto a comunicação via satélite e a queda dos custos de transporte possibilitaram cada vez mais a difusão imediata dessas decisões num espaço cada vez mais amplo e variegado".

Em conseqüência do aumento dos poderes de flexibilidade e mobilidade, os empregadores passaram a exercer maior controle sobre a força de trabalho; o trabalho organizado ficou abalado pela "reconstrução de focos de acumulação flexível" em regiões sem tradição industrial e pela "reimportação", para os centros mais antigos, das práticas e normas estabelecidas nessas novas áreas. Isso, ao que parece, devido à acumulação flexível "os níveis relativamente altos de desemprego 'estrutural', a rápida destruição e reconstrução de habilidades, ganhos modestos (quando há) de salários reais e o retrocesso do poder sindical - uma das colunas políticas do regime fordista" (idem, p. 141). 
Considerando que a acumulação flexível é uma forma de capitalismo, é esperado que algumas proposições básicas permaneçam. Nesse sentido, cabe lembrar as três condições necessárias do modo capitalista de produção propostas por Marx, que foi capaz de mostrar que estas eram inconsistentes e contraditórias, e que, por isso, a dinâmica do capitalismo era necessariamente propensa a crises[5] (Harvey, idem, p. 164): o capitalismo é orientado para o crescimento[6]; o crescimento em valores reais se apóia na exploração do trabalho vivo na produção,[7] o capitalismo é, por necessidade, tecnológica e organizacionalmente dinâmico.[8]

O argumento marxista é, por conseguinte, que a tendência de superacumulação nunca pode ser eliminada sob o capitalismo. Trata-se de um interminável e eterno problema de todo modo capitalista de produção. A única questão, portanto, é "como exprimir, conter, absorver ou administrar essa tendência" de modo a não ameaçar a ordem social capitalista, e isso implica em escolhas reais "para que a ordem social não se transforme em caos" (idem, p. 170):

a) Desvalorização de: mercadorias, capacidade produtiva, valor do dinheiro

Talvez associada à destruição direta, fornece um modo de lidar com excedentes de capital. A força de trabalho também pode ser "desvalorizada e até destruída" devido às taxas crescentes de exploração, à queda da renda real, ao desemprego, ao aumento de mortes no trabalho, à piora da saúde e menor expectativa de vida etc[9].

\section{b) Controle macroeconômico}

Pode conter o problema da superacumulação, por meio da institucionalização de algum sistema de regulação, talvez por um considerável período de tempo.[10] Entretanto, cabe lembrar que "foi necessária uma grande crise de superacumulação para ligar a produção fordista a um modo keynesiano de regulamentação estatal antes de se poder garantir, por qualquer período estendido, alguma espécie de crescimento macroeconômico equilibrado" (idem, p. 170). Trata-se, então, de considerar que "a ascensão de um regime particular de acumulação" é resultado de todo um conjunto de decisões econômicas e políticas (nem sempre dirigidas conscientemente para um fim específico) provocadas pela persistência de manifestações da superacumulação (idem).

\section{c) Absorção da superacumulação}

Pelo deslocamento temporal e espacial, oferece um "terreno mais rico e duradouro", porém muito mais problemático, no qual tentar controlar o problema da superacumulação[11].

\subsection{Acumulação flexível: mais-valia combinada}


Na acumulação flexível, Harvey vê uma "recombinação simples" de mais-valia absoluta e mais-valia relativa, que são as duas estratégias para obtenção do lucro, definidas por Marx.

A mais-valia absoluta é apoiada na extensão da jornada de trabalho em termos do salário necessário para garantir a reprodução da classe trabalhadora, em relação a um dado padrão de vida. Conforme sinaliza Harvey (idem, p. 174), "a passagem para mais horas de trabalho associadas com uma redução geral do padrão de vida através da erosão do salário real ou da transferência do capital corporativo de regiões de altos salários para regiões de baixos salários representa uma faceta da acumulação flexível de capital", ressaltando ainda esse autor que "muitos dos sistemas padronizados de produção construídos sob o fordismo foram, por essa razão, transferidos para a periferia, criando o "fordismo periférico".[12]

Na mais-valia relativa, a mudança organizacional e tecnológica "é posta em ação para gerar lucros temporários para firmas inovadoras e lucros mais generalizados com a redução dos custos dos bens que definem o padrão de vida do trabalho" (idem, ibidem).

Também aqui a violência proliferante dos investimentos, que cortou o emprego e os custos do trabalho em todas as indústrias - mineração de carvão, produção de aço, bancos e serviços financeiros -, foi um aspecto deveras visível da acumulação do capital nos anos 80 . Mas apoiar-se nessa estratégia enfatiza a importância de forças de trabalho altamente preparadas, capazes de compreender, implementar e administrar os padrões novos, mas muito mais flexíveis, de inovação tecnológica e orientação do mercado. Surge então um estrato altamente privilegiado e até certo ponto poderoso da força de trabalho, à medida que o capitalismo depende cada vez mais da mobilização de forças de trabalho intelectual como veículo para mais acumulação (idem, p. 174).

O que conta, no final, diz Harvey, é o modo particular como as estratégias absoluta e relativa se combinam e se alimentam mutuamente. Esse autor chama atenção para o curioso fato de que o desenvolvimento de novas tecnologias gerou excedentes de força de trabalho que tornaram mais viável o retorno de estratégias absolutas de extração de maisvalia, até mesmo nos países capitalistas avançados. Entretanto, o que Harvey avalia como talvez mais inesperado é o modo como as novas tecnologias de produção e as novas formas de coordenar a organização do trabalho favoreceram o retorno dos sistemas de trabalho doméstico, familiar e paternalista, considerando a tendência de Marx em supor que estes "sairiam do negócio ou seriam reduzidos a condições de exploração cruel e de esforço desumanizante a ponto de se tornarem intoleráveis sob o capitalismo avançado".

O retorno da superexploração em Nova lorque e Los Angeles, do trabalho em casa e do "teletransporte", bem como o enorme crescimento das práticas de trabalho do setor informal por todo o mundo capitalista avançado, representa de fato uma visão bem sombria da história supostamente progressista do capitalismo

(idem, p. 175). 
Estaria havendo o que Harvey denomina de "ecletismo nas práticas de trabalho?" De fato, parece que as condições imprimidas pela acumulação flexível estão favorecendo a coexistência de sistemas de trabalho alternativos num mesmo espaço, facilitando aos empreendedores capitalistas a escolha. Assim, adotando o exemplo desse autor (idem, ibidem), "o mesmo molde de camisa pode ser produzido por fábricas de larga escala na Índia, pelo sistema cooperativo da 'Terceira Itália', por exploradores em Nova lorque e Londres ou por sistemas de trabalho familiar em Hong Kong".

\section{O mercado de trabalho em condições de acumulação flexível}

É fato que o mercado de trabalho reestruturou-se, e de forma radical. Regimes e contratos de trabalho mais flexíveis passaram a ser impostos, tendo em vista o enfraquecimento do poder sindical e a grande quantidade de mão-de-obra excedente, os desempregados ou subempregados, em conseqüência da "forte volatilidade" do mercado, do aumento da competição e do "estreitamento" das margens de lucro. Partindo dessa análise, Harvey (idem) imagina ser difícil esboçar um quadro geral claro, considerando que o objetivo dessa flexibilidade é "satisfazer as necessidades com freqüência muito específicas de cada empresa". Observa que mesmo em relação aos empregados regulares vêm se tornando muito mais comuns sistemas como "nove dias corridos" ou jornadas de trabalho com, em média, quarenta horas semanais ao longo do ano, mas que, por outro lado, "obrigam o empregado a trabalhar em períodos de redução da demanda". Mas é à "aparente redução" do emprego regular (que vem favorecendo o crescente uso do trabalho em tempo parcial, temporário ou subcontratado) que Harvey atribui maior importância, ao analisar a estrutura do mercado de trabalho em condições de acumulação flexível:[13]

O centro é um grupo que diminui cada vez mais e é composto por empregados "em tempo integral, condição permanente e posição essencial para o futuro de longo prazo da organização". Goza de maior segurança no emprego, boas perspectivas de promoção e reciclagem. Tem garantia de pensão, seguro e "outras vantagens indiretas relativamente generosas". É esperado que esses trabalhadores sejam adaptáveis, flexíveis, com mobilidade geográfica, caso seja necessário. Em época de dificuldade na empresa, mesmo empregados que desenvolvem funções de alto nível (que vão de projetos à propaganda e à administração financeira) podem ser substituídos por empregados subcontratados, devido aos custos potenciais da dispensa temporária nesse grupo central, sendo, no entanto, mantido um grupo de gerentes relativamente pequeno.

A periferia abrange dois subgrupos "bem distintos". O primeiro grupo periférico é composto de empregados em tempo integral, com habilidades facilmente disponíveis no mercado de trabalho (como pessoal do setor financeiro, secretárias, pessoal das áreas de trabalho rotineiro e de trabalho manual menos especializado). São trabalhadores com menos acesso a oportunidades de carreira, levando esse grupo a se caracterizar por uma alta 
taxa de rotatividade, "o que torna as reduções da força de trabalho relativamente fáceis por desgaste natural".

O segundo grupo periférico: numericamente, a flexibilidade neste grupo é maior do que no primeiro periférico e inclui empregados em tempo parcial, empregados casuais, pessoal com contrato por tempo determinado, temporários, subcontratados e treinandos com subsídio público. Neste grupo há ainda menos segurança de emprego. Evidencia-se um "crescimento bastante significativo" desta categoria nos últimos anos.

Esses "arranjos" de emprego flexíveis em si não criam, segundo Harvey, uma forte insatisfação trabalhista, pois a flexibilidade pode ser, às vezes, benéfica para ambos os lados. Contudo, sob o ponto de vista dos trabalhadores como um todo, os "efeitos agregados" parecem não ser nada positivos, quando consideramos a cobertura de seguro, os direitos de pensão, os níveis salariais e a segurança no emprego.

O aumento da subcontratação e do trabalho temporário parece indicar a direção mais radical da mudança, e não o trabalho em tempo parcial, sinaliza Harvey, argumentando que no Japão esse é um padrão seguido há muito e que, mesmo no fordismo, a subcontratação de pequenas empresas "agia como protetor das grandes corporações do custo das flutuações do mercado". E, assim, esse autor admite que a atual tendência dos mercados de trabalho é a redução do número de trabalhadores "centrais" e a ampliação do emprego de uma força de trabalho facilmente admitida e descartada sem custos, quando a empresa vai mal.

Evidentemente, isso não mudou de maneira radical os problemas, surgidos nos anos 60 , dos mercados de trabalho "duais" ou segmentados, mas o reformulou segundo uma lógica bem diferente. Embora seja verdade que a queda da importância do poder sindical reduziu o singular poder dos trabalhadores brancos

do sexo masculino nos mercados do setor monopolista, não é verdade que os excluídos desses mercados de trabalho - negros, mulheres, minorias étnicas de todo tipo - tenham adquirido uma súbita paridade (exceto no sentido de que muitos operários homens e brancos foram marginalizados, unindo-se aos excluídos) (idem, p. 145).

A transformação na estrutura do mercado de trabalho também se verificou, com igual importância, na organização industrial. A subcontratação organizada, por exemplo, "abre oportunidades para a formação de pequenos negócios e, em alguns casos, permite que sistemas mais antigos de trabalho doméstico, artesanal, familiar (patriarcal) e paternalista ("padrinhos", "patronos" e até estruturas semelhantes à da máfia) revivam e floresçam, mas agora como peças centrais, e não apêndices do sistema produtivo" (idem, p. 145). O rápido crescimento de economias "negras", "informais" ou "subterrâneas" também tem sido documentado em todo o mundo capitalista avançado, "levando alguns a detectar uma crescente convergência entre sistemas de trabalho "terceiromundistas" e capitalistas avançados" (idem). Contudo, alerta Harvey, "a ascensão" de novas formas de organização 
industrial e o retorno de formas mais antigas[14] têm significações distintas em diferentes lugares. Podem em alguns casos indicar o surgimento de novas estratégias de sobrevivência para pessoas desempregadas ou totalmente discriminadas, em outros casos podem representar grupos imigrantes buscando "entrar num sistema capitalista, formas organizadas de sonegação de impostos ou o atrativo de altos lucros no comércio ilegal em sua base", casos cujo efeito é uma "transformação do modo de controle do trabalho e de emprego".

Com efeito, uma das grandes vantagens do uso dessas formas antigas de processo de trabalho e de produção pequeno-capitalista é o solapamento da organização da classe trabalhadora e a transformação da base da luta de classes.

Nelas, a consciência de classe já não deriva da clara relação de classe entre capital e trabalho, passando para um terreno muito confuso dos conflitos interfamiliares e das lutas pelo poder num sistema de parentescos ou semelhantes a um clã que contenha relações sociais hierarquicamente ordenadas. A luta contra a exploração capitalista na fábrica é bem diferente da luta contra um pai ou um tio que organiza o trabalho familiar num esquema de exploração altamente disciplinado e competitivo que atende às encomendas do capital multinacional (idem, p. 145).

É surpreendente, se concordarmos com a observação de Harvey, como o capitalismo tem cada vez mais se organizado "através da dispersão, da mobilidade geográfica e das respostas flexíveis nos mercados de trabalho, nos processos de trabalho e nos mercados de consumo", para isso contribuindo uma grande recorrência à inovação tecnológica, de produtos e institucional. Harvey atribui a dois importantes desenvolvimentos paralelos 0 alcance da "organização mais coesa e da centralização implosiva".

O primeiro desenvolvimento enfatiza o papel da informação. Informações precisas e atualizadas transformaram-se numa valiosa mercadoria.[15]

A ênfase na informação também gerou um amplo conjunto de consultorias e serviços altamente especializados capazes de fornecer informações quase minuto a minuto sobre tendências de mercado e o tipo de análise instantânea de dados útil para as decisões corporativas. Ela também criou uma situação em que vastos lucros podem ser realizados com base no acesso privilegiado às informações, em particular nos mercados monetários e financeiros (...). Mas isso é, em certo sentido, apenas a ponta de um iceberg em que o acesso privilegiado a informações de qualquer espécie (tais como conhecimentos científicos e técnicos, políticas do governo e mudanças políticas) passa a ser um aspecto essencial das decisões bem-sucedidas e lucrativas (idem, p.151).

Embora o acesso ao conhecimento científico e técnico sempre tenha sido importante como elemento de competitividade, agora são percebidos uma ênfase e um interesse renovados, já que as constantes mudanças ("de gostos, necessidades e os sistemas de produção flexíveis, o conhecimento da última técnica, do mais novo produto, da mais recente descoberta científica etc.") implicam a possibilidade de vantagens na concorrência. O próprio saber se tornou uma "mercadoria-chave" na luta competitiva. Universidades e instituições de pesquisa entram em uma feroz competição por pessoal, por ser o primeiro a 
patentear novas descobertas científicas. A produção organizada de conhecimento teve uma expansão extraordinária nas últimas décadas, mas ao mesmo tempo adquiriu cada vez mais um cunho comercial (idem).

O segundo desenvolvimento, e podemos concordar com Harvey, foi muito mais importante do que o primeiro. Trata-se da "completa reorganização do sistema financeiro global" e da "emergência de poderes imensamente ampliados de coordenação financeira". O dualismo uma vez mais está presente no movimento do capital, levando, de um lado, à formação de conglomerados e corretores financeiros com um poder global extraordinário, e de outro, a uma "rápida proliferação e descentralização de atividades e fluxos financeiros por meio da criação de instrumentos e mercados financeiros totalmente inéditos" (idem, p. 152).

Com a implementação dos novos sistemas financeiros, a partir de 1972, deu-se uma mudança no equilíbrio de forças no capitalismo global e o sistema bancário e financeiro passou a dispor de muito mais autonomia em comparação ao financiamento corporativo, estatal e pessoal. Não resta dúvida de que a acumulação flexível recorre mais do que o fordismo ao capital financeiro "como poder coordenador", o que significa uma potencialidade, muito maior do que antes, de crises financeiras e monetárias "autônomas e independentes".[16]

\section{Modernas formas de flexibilidade: ocultamento de um sistema de poder}

Uma das sérias conseqüências do capitalismo "flexível" é a perda da noção de carreira para os trabalhadores. Obrigados a saírem de um emprego para outro, estes vêem interrompida a expectativa de construção de uma carreira ao longo da vida. A flexibilidade retoma, assim, o sentido original da palavra emprego no século XIV, na medida em que hoje "as pessoas fazem blocos, partes de trabalho, no curso de uma vida", como antigamente iriam fazer alguma coisa que pudessem transportar numa carroça de um lado para o outro.[17]

Segundo Sennett, as modernas formas de flexibilidade ocultam um sistema de poder caracterizado pela reinvenção descontínua de instituições; especialização flexível de produção e concentração de poder sem centralização.

\subsection{Reinvenção descontínua de instituições.}

Há uma tendência hoje na literatura dos negócios a retratar o desejo de mudança como uma das características exigidas do comportamento flexível. Entretanto, ressalta Sennett, trata-se na verdade de um determinado tipo de mudança que tem certas conseqüências para nosso "senso de tempo". Se num sentido parece haver continuidade em relação ao que passado, em outro parece ter havido um rompimento. Assim, na esfera do trabalho, a continuidade se dá pelo sentido de tempo mutante, mas contínuo, enquanto a ruptura, em 
contraste, espera que o tempo se torne descontínuo. Promovendo a descontinuidade do presente com o passado, a mudança flexível, do tipo que hoje ataca a rotina burocrática, busca, na visão de Sennett (idem, p. 55), "reinventar decisiva e irrevogavelmente as instituições".

Para "reinventar" as instituições, os administradores valem-se de técnicas específicas, como usar programas de computador que padronizam procedimentos operacionais para, por exemplo, "oferecer a um menor número de administradores controle sobre um maior número de subordinados". Práticas como essa são conhecidas pelo termo "reengenharia", que, na realidade sugere fazer mais com menos, destacando-se, portanto, como seu maior atributo a redução de empregos. Mas essa sugestão de eficiência é eficiência é "enganosa", diz Sennett, considerando que "a mudança irreversível se dá precisamente porque a reengenharia pode ser um processo altamente caótico" (idem, p. 56).[18]

A flexibilidade veio particularmente combater os males da rotina em nome de maior produtividade, mas talvez se possa duvidar de que o atual momento seja mais produtivo do que o passado recente, se considerarmos a redução das taxas de produtividade observadas em todas as grandes sociedades industriais. Os avanços na tecnologia de fato propiciaram um significativo aumento no setor de manufatura de alguns países, mas, considerando-se todas as formas de trabalho, de escritório e de fábrica, "a produtividade reduziu-se no todo, quer seja medida em termos de produção de trabalhadores individuais ou de hora de trabalho" (idem, p. 57).[19] Mas, na concepção de Sennett, há motivos fundamentais ocultos no moderno capitalismo para buscar uma "mudança decisiva, irreversível, por mais desorganizada ou improdutiva que seja". Trata-se da volatilidade da demanda do consumidor, que, segundo esse autor, produz uma segunda característica dos regimes flexíveis, que é a "especialização flexível de produção".

\subsection{Especialização flexível.}

A especialização flexível opõe-se radicalmente ao sistema de produção incorporado no fordismo. Ilhas de produção especializada vieram substituir as a velha e quilométrica linha de montagem (observada por Daniel Bell). Em várias dessas fábricas flexíveis na autoindústria "é importante a inovação em resposta à demanda do mercado, mudando-se as tarefas semanais, e às vezes até diárias, que os operários têm de cumprir" (idem, p. $60)$.

A alta tecnologia e a rapidez das modernas comunicações favorecem a especialização flexível. O computador permite a fácil reprogramação e configuração das máquinas industriais. Através dos modernos meios de comunicação, dados do mercado global ficam ao alcance imediato da empresa. Como essa forma de produção exige rápida tomada de decisões, tornam-se mais adequados grupos de trabalho pequenos, diferentemente do que 
ocorria no fordismo, com sua grande pirâmide burocrática.

\subsection{Concentração sem centralização de poder.}

As mudanças nas redes, mercados e produção que um regime flexível utiliza permitem o que Sennett chama de "concentração de poder sem centralização de poder".

È corrente a afirmação de que a nova organização do trabalho descentraliza o poder, ou seja, permite às pessoas nas categorias inferiores das organizações maior controle sobre as próprias atividades. Mas, conforme demonstra Sennett, tal afirmação não se sustenta. Hoje, os altos administradores têm uma visão abrangente da organização, graças aos novos sistemas de informação, o que não deixa muito espaço aos indivíduos para "esconder-se" em qualquer parte da rede. Do mesmo modo, "a desagregação vertical[20] e a eliminação de camadas[21] são tudo, menos processos descentralizantes” (idem, p. 64).

Uma característica administrativa freqüente na reorganização empresarial é sobrecarregar pequenos grupos de trabalho com muitas tarefas. E, assim, novas formas de poder "desigual e arbitrário" dentro da organização vêm se juntar à "economia da desigualdade" (idem, ibidem). A essa maneira de transmitir a operação de comando, , Sennett denomina "concentração sem centralização" - uma estrutura institucional sem a visibilidade da antiga forma piramidal, mas que nem por isso tornou-se mais simples, ao contrário, trata-se de uma estrutura complexa e considerá-la como um processo de "desburocratização" é um engano. Nas modernas organizações que praticam a concentração sem centralização, segundo Sennett (idem, p. 65), "a dominação do alto é ao mesmo tempo forte e informe".

\section{4. "Flexitempo": o tempo no local de trabalho.}

Os três elementos que constituem o regime flexível, apontados por Sennett, podem ser compreendidos pela forma como se articulam na organização do tempo no local de trabalho.

O chamado "flexitempo" é um termo bem apropriado para designar as experiências com vários horários que as organizações flexíveis hoje estão fazendo. A organização do horário de trabalho perdeu a rigidez dos turnos fixos, sempre o mesmo, mês após mês. Trata-se agora de organizar horários de trabalho diferentes, mais individualizados, transformandose assim o dia de trabalho num mosaico, como expressivamente o compara Sennett.

O flexitempo surgiu da entrada de mais mulheres da classe média no mundo do trabalho [22], pois a condição de mães e os afazeres domésticos exigiam das trabalhadoras maior flexibilidade de horário, o que acabou contribuindo para a inovação do planejamento flexível do tempo integral e de meio período. Hoje, conforme observa Sennett, tais 
mudanças ultrapassaram a barreira dos gêneros, já que também os homens podem ter horários maleáveis. Entretanto, embora pareça que tal flexibilidade permite ao trabalhador maior liberdade do que ao ficar submetido à rotina da fábrica, ocorre justamente o contrário, pois, como adverte esse autor, o trabalhador ficou inserido numa "nova trama de controle". A programação flexível do tempo[23], na realidade, constitui-se mais numa vantagem do que num direito trabalhista, ou seja, num "benefício distribuído de maneira desigual e estritamente racionado", hoje aplicado apenas em países como Estados Unidos.

Essa nova trama de controle pode ser exemplificada com "o mais flexível dos flexitempos" - o trabalho em casa -, levando-nos a concluir com Sennett, que "se o flexitempo é a recompensa do empregado, também o põe no domínio íntimo da instituição” (idem, p. 68). Segundo esse autor, trata-se de "prêmio" que provoca grande ansiedade nos empregadores, pelo medo de perderem o controle sobre os trabalhadores ausentes e de que os que trabalham em casa abusem dessa liberdade. E tal preocupação levou à criação de vários tipos de controle para regular os processos de trabalho concreto dos trabalhadores ausentes do escritório, como: exigência de contatos telefônicos regulares com o escritório; monitoramento intra-rede; abertura freqüente dos e-mails pelos supervisores. Isto vem evidenciar que, embora o trabalhador tenha o controle do local de trabalho, o flexitempo não lhe permite assumir maior controle sobre o próprio processo de trabalho e, conforme vários estudos vêm sugerindo, muitas vezes é maior a supervisão do trabalho sobre os ausentes do escritório do que em relação aos presentes (idem). O que ocorreu foi uma mudança na forma de controle, ou seja, os trabalhadores passaram a ser submetidos, não mais a um controle presencial, mas a um controle "eletrônico", virtual. Ou, como diz Sennett (idem, p. 68), a "lógica métrica" do tempo de Daniel Bell passou do relógio de ponto para a tela do computador, "porém, se o trabalho tornou-se fisicamente descentralizado, ficou mais direto o poder sobre o trabalhador". Trabalhar em casa, "é a ilha última do novo regime" - diz esse autor.

\section{Subjetividade: da rotina do fordismo à fragmentação do regime flexível}

Caráter é uma construção histórica, pois se nada é "enraizado" na natureza humana, características humanas não são dadas a priori. De acordo com o sistema moral de Marx, o homem "não é a contrapartida animal de uma série de ideais morais abstratos", posto que pode tornar-se o que é (bom, mau, egoísta, ou qualquer outra coisa) em qualquer momento, conforme as circunstâncias predominantes e é nesse sentido que ele é o "ser automediado da natureza e do homem" (Mészáros, 1981, p. 147). Por outro lado, conforme o define Sennett (1999, p. 10), caráter significa "traços pessoais a que damos valor em nós mesmos, e pelos quais buscamos que os outros nos valorizem". Sob esses dois prismas podemos melhor entender a formação do caráter na rotina do fordismo ou na fragmentação do regime flexível de trabalho. 


\subsection{A rotina do fordismo e a formação do caráter}

Adam Smith, entendendo ser o caráter formado pela história e seus movimentos imprevisíveis, pensava sobre a influência da rotina na formação do caráter. Segundo ele, para desenvolvermos nosso caráter precisamos fugir da rotina, posto que não há muito a fazer em termos de história, a partir do momento em que ela é estabelecida (Sennett, idem). Com essa proposição geral, Smith enalteceu o caráter do homem de negócios, considerando-o o "ser humano mais plenamente engajado", que agia "em reação e com simpatia às cambiantes exigências do momento" (idem, p. 43). Por outro lado, inspiravaIhe pena o estado de caráter dos trabalhadores industriais atrelados à rotina. Os males da rotina - a divisão do trabalho sem o controle deste pelo trabalhador - descritos por Smith, iriam fornecer elementos à análise de Marx sobre a transformação do tempo em produto [24].

As preocupações com o tempo de rotina no capitalismo industrial que acabava de surgir em fins do século dezoito chegam ao século XX, com o fordismo. Antes de Ford, a indústria automobilística se baseava no artesanato, com trabalhadores altamente qualificados e que gozavam de grande autonomia, fazendo serviços complexos nas diferentes partes de um automóvel durante todo um dia de trabalho. Segundo Sennett (idem, p. 44), a indústria de automóveis era, na verdade, "um conjunto de lojas descentralizadas", mas de 1910 a 1914, quando Henry Ford industrializou seu processo de produção, sua a fábrica[25] foi considerada "um ilustre exemplo da divisão do trabalho em bases tecnológicas". Nessa época, Ford privilegiou os empregos dos chamados trabalhadores especialistas (operavam em miniaturas que exigiam pouco pensamento ou julgamento) em relação aos artesãos qualificados. Em 1917, o maior contingente (55\%) da força de trabalho era de especialistas[26].

Entretanto, a escravidão ao tempo rotineiro não foi aceita passivamente, posto que os trabalhadores sabotavam a administração do tempo-movimento (os estudos de Taylor) e ignoravam as especificações de métodos e processos de trabalho sempre que estes contrariavam seus interesses. Além disso, deprimidos, reduziam sua produtividade.

Na década de 1950, a fábrica[27] transformou-se. Imensa e bem engrenada, operava com base em três princípios: a lógica da dimensão, a lógica da hierarquia e a lógica do tempo métrico.

A lógica da dimensão era simples: "maior, mais eficiente". A concentração de todos os elementos de produção num lugar levava a economizar energia, poupar no transporte de materiais e facilitava a interligação da fábrica com os trabalhadores de escritório e executivos. 
Na lógica da hierarquia é "superestrutura" que organiza e dirige a produção, extrai todo trabalho cerebral possível da fábrica. Tudo é centralizado nos departamentos de planejamento, cronograma e projeto, o que fazia os técnicos e administradores ficarem o máximo possível distantes da maquinaria, deixando "o trabalhador da base, cuidando só de detalhes, divorciado de qualquer decisão ou modificação em relação ao produto no qual está trabalhando" (Daniel Bell, apud Sennett, idem, p. 47).

Na lógica taylorista do "tempo métrico", o tempo é minuciosamente calculado em toda parte na vasta fábrica, permitindo aos altos administradores saber com precisão sobre o trabalho que cada um deveria estar realizando num dado momento. $O$ "planejamento minucioso do tempo de trabalho" também era utilizado no pagamento por antigüidade. Este era "finamente sintonizado" com o número total de horas trabalhadas na fábrica; um trabalhador podia "calcular minuciosamente" os benefícios do tempo de férias e ausência por doença. A "micrométrica do tempo" regia as promoções e os benefícios, tanto dos escalões inferiores dos escritórios, como dos trabalhadores braçais na linha de montagem.

A métrica do tempo, contudo, transformara-se em outra coisa que não um ato de repressão e dominação praticada pela administração em nome do crescimento da gigantesca organização industrial. Para os trabalhadores, o tempo rotinizado tornara-se uma "arena", diz Sennett, onde podiam afirmar suas próprias exigências e poder.

\subsection{Trabalho flexível e subjetividade: uma "guerra sem recurso às armas[28]"}

Há pessoas com capacidade de maior mobilidade no novo capitalismo. São pessoas com determinados traços de caráter, como "capacidade de desprender-se do próprio passado" e "confiança para aceitar a fragmentação", traços que geram a espontaneidade (Sennet, idem, p. 73). Entretanto, esses mesmos traços têm um efeito autodestrutivo para aqueles empregados mais comuns que "tentam jogar segundo as mesmas regras" no regime flexível. Esses têm seu caráter corroído pelo novo sistema de poder flexível.

Segundo Dejours, vivemos numa guerra econômica entre os países que tem a competitividade como arma central. A idéia de que uma ameaça de quebra ronda os países foi naturalizada. Em nome da "sobrevivência da nação" e da "garantia da liberdade", é justificada a entrada nessa guerra, mesmo à custa da utilização de "métodos cruéis" no mundo do trabalho (Dejours, 1999, p. 13).

No mercado de trabalho, os considerados inaptos para o combate nessa "guerra econômica" são demitidos da empresa, como "os velhos que perderam a agilidade, os jovens mal preparados, os vacilantes". Quanto aos "aptos”, deles são exigidos os maiores desempenhos em relação a produtividade, disponibilidade, disciplina e abnegação. E é 
assim, da nossa eficácia frente aos nossos concorrentes, que depende nossa sobrevivência.

Com essa perspectiva, Dejours defende a tese de que essa guerra implica "sacrifícios individuais consentidos" e "sacrifícios coletivos decididos em altas instâncias", em nome da "razão econômica". Entretanto, pensa Dejours, essa guerra não tem origem unicamente na natureza do sistema econômico, no mercado ou na globalização, mas também nas condutas humanas. A questão desse autor é saber sobre as "motivações subjetivas do consentimento".

\subsubsection{O sofrimento no trabalho e suas causas}

A tese defendida por Dejours (1999), de que por meio do sofrimento no trabalho se forma o consentimento para participar do sistema, traz grande contribuição ao debate sobre a produção de subjetividade no mundo do trabalho flexível. Segundo esse ponto de vista, o sofrimento para os que trabalham aumenta na medida em que vão perdendo a esperança de melhorar sua condição de vida no futuro. A relação com o trabalho vai perdendo o sentido, dissociando-se da promessa de felicidade e segurança compartilhadas para si, os colegas, os amigos e os próprios filhos. O sofrimento vai aumentando pela não correspondência entre o esforço no trabalho e a possibilidade de satisfazer as expectativas criadas no plano material, afetivo, social e político.

Entretanto, esse autor chama a atenção para o fato de que o sofrimento não desativa a "maquinaria de guerra econômica", ao contrário, ele a alimenta por meio de uma "sinistra inversão", em que homens e mulheres criam estratégias de defesa contra o sofrimento padecido no trabalho. São estratégias sutis, engenhosas, diversificadas e criativas. Mas também, tais estratégias contêm uma "armadilha", alerta Dejours, para os que conseguem suportar o sofrimento sem se abater, mostrando-se necessário, portanto, tomar-se consciência do sofrimento no trabalho.

A realidade mostra as diversas causas do sofrimento dos que trabalham. Estes sofrem por freqüentes infrações das leis trabalhistas; por enfrentarem riscos, como radiações, vírus; porque se submetem a horários alternados etc.; por temerem não satisfazer as imposições da organização do trabalho quanto a horário, ritmo, formação, informação, aprendizagem, nível de instrução e de diploma, experiência, rapidez de aquisição de conhecimentos teóricos e práticos (Dessors \& Torrente, 1996, apud Dejours, idem), bem como por não se adaptarem à "cultura" ou à "ideologia" da empresa, às exigências do mercado, às relações com os clientes, os particulares ou o público etc. (Dejours, idem, p. 28). Esse sofrimento no trabalho é "amplamente ignorado", segundo Dejours, e tem como causas:

a) Medo da incompetência 
Nas situações comuns de trabalho, não importa as qualidades da organização do trabalho e da concepção, é "impossível" cumprir os objetivos da tarefa "respeitando escrupulosamente" as prescrições, as instruções e os procedimentos. Há situações em que ocorrem falhas e o trabalhador, muitas vezes, não tem como saber se a anomalia surgida é do sistema (técnico, por exemplo), ou devido à sua própria incompetência. $A$ perplexidade diante do fato acaba gerando angústia e sofrimento, que tomam a forma de "medo de ser incompetente", de "não estar à altura" ou de se mostrar "incapaz de enfrentar" adequadamente situações incomuns ou incertas, que exigem responsabilidade.

\section{b) Pressão para trabalhar mal}

Aqui não se trata de ter ou não competência e habilidade. Mesmo quando o trabalhador sabe o que deve fazer, não o consegue, já que pressões sociais do trabalho o impedem, como, por exemplo: colegas criam-Ihe obstáculos, o ambiente social é péssimo, cada um trabalha por si, enquanto os demais sonegam informações, prejudicando a cooperação. Segundo Dejours (idem, p. 32), "ser constrangido a executar mal o seu trabalho, a atamancá-lo ou a agir de má-fé é uma fonte importante e extremamente freqüente de sofrimento no trabalho, seja na indústria, nos serviços ou na administração".

\section{c) Falta de esperança no reconhecimento}

O reconhecimento não é uma reivindicação sem maior importância para os que trabalham. Ao contrário, ele assume papel decisivo na dinâmica da "mobilização subjetiva da inteligência e da personalidade" no trabalho, ou, como é denominado em psicologia, "motivação no trabalho". Se não puder usufruir os benefícios do reconhecimento do seu trabalho e encontrar dessa forma o sentido da sua relação com ele, a pessoa sofre, e é um sofrimento tão "absurdo" e recorrente, que acaba desestabilizando a identidade e a personalidade, e levando à loucura.

\section{d) Sofrimento e defesa}

Apesar de esperado por todos os trabalhadores, o reconhecimento pelo trabalho efetivado raramente acontece de modo satisfatório, sendo de se esperar que o sofrimento no trabalho acabe gerando uma "série de manifestações psicopatológicas". Se, entretanto, o sofrimento não se manifesta numa ruptura do equilíbrio psíquico, é porque "contra ele o sujeito emprega defesas que lhe permitem controlá-lo" (idem, p. 35). Além dos clássicos mecanismos de defesa, existem "estratégias coletivas de defesa", que, especificamente marcadas pelas pressões reais do trabalho, são construídas e empregadas pelo conjunto dos trabalhadores.

Dejours procura mostrar que essas estratégias defensivas, entretanto, podem também se 
transformar em "armadilha", tornando os trabalhadores insensíveis ao que faz sofrer. Além disso, diz esse autor, às vezes criam uma tolerância ao sofrimento, não apenas psíquico, mas ao "sofrimento ético", ou seja, permitem ao sujeito tolerar o sofrimento que, embora o condenando moralmente, inflige a outrem, em virtude do seu trabalho. Como é provável que tal sofrimento também acometa aquele que assim age, adverte Dejours, para este manter seu equilíbrio psíquico deverá ser capaz de construir defesas contra tal sofrimento.

Por outro lado, encontram muitas dificuldades para reagir coletivamente os que sofrem "por causa da intensificação do trabalho, por causa do aumento da carga de trabalho e da fadiga, ou ainda por causa da degradação progressiva das relações de trabalho", como arbitrariedade das decisões, desconfiança, individualismo, concorrência desleal entre agentes, arrivismo desenfreado etc. (idem, p. 43).

Em termos de precarização do trabalho, Dejours apresenta quatro efeitos. O primeiro, é a intensificação do trabalho e o aumento do sofrimento subjetivo. O segundo, a neutralização da mobilização coletiva contra o sofrimento, a dominação e a alienação. O terceiro, é a estratégia defensiva do não falo, não vejo, não ouço, indicando que, antes de tudo, devese resistir e para isso é necessário ficar alheio ao sofrimento e à injustiça infligidos a outrem. E o quarto, é o individualismo, o cada um por si.

Contudo, a precarização não é específica dos trabalhadores precários, pois são atingidos, também, com grandes conseqüências, a vivência e a conduta dos que trabalham. Afinal, conforme argumenta Dejours, são os empregos destes que se precarizam, tendo em vista a possibilidade de se recorrer a empregos precários para substituí-los ou a demissões, ao menor deslize praticado pelo trabalhador.

\subsubsection{Organização do trabalho: entre o prescrito e o real, a disciplina e o zelo}

É próprio das empresas, instituições e serviços um grande problema na organização do trabalho: a defasagem entre a organização prescrita e a real, independente do grau de refinamento das prescrições e dos métodos de trabalho (Dejours, idem). Não é possível prever tudo antecipadamente à situação real. O suposto trabalho de execução, diz esse autor, "nada mais é do que uma quimera", pois o processo de trabalho "só funciona" quando os trabalhadores mobilizam sua inteligência, individual e coletivamente, em benefício da organização do trabalho.

Uma fábrica, uma usina, ou um serviço só funcionam quando os trabalhadores, por conta própria, usam de artimanhas, macetes, quebra-galhos, truques; quando se antecipam, sem que Ihes tenham explicitamente ordenado, a incidentes de toda a sorte; quando, enfim, se ajudam mutuamente, segundo os princípios de cooperação que eles inventam e que não lhes foram indicados de antemão (idem, p. 56).

O exercício dessa inteligência no trabalho, entretanto, adverte o autor, geralmente só é 
possível infringindo os regulamentos e ordens, ou seja, não basta o trabalhador apenas dar mostras de inteligência para suprimir a defasagem entre a organização do trabalho prescrita e a organização do trabalho real, pois muitas vezes essa inteligência só pode ser usada "semiclandestinamente".

A essas características da "inteligência eficiente no trabalho" denomina-se "zelo" no trabalho. São características cognitivas e afetivas. Como característica cognitiva trata-se de saber lidar com o imprevisto, o inusitado, o que ainda não foi assimilado, rotinizado. Quanto às afetivas, é ousar desobedecer ou transgredir, agir inteligentemente, mas de forma clandestina, ou discretamente.

Frente a essas características, trata-se de questionar o poder da disciplina sobre a qualidade do trabalho. Com sua análise crítica sobre o tema, Dejours (p. 57) traz a seguinte argumentação: "Se o sistema nazista de produção e administração funcionava é porque os trabalhadores e o povo contribuíam em massa com sua inteligência e engenhosidade para torná-lo eficaz. Se eles tivessem observado rigorosamente a disciplina, o sistema teria sido paralisado".

\subsubsection{Medo: o novo "motor" da inteligência no trabalho}

Em pesquisas recentes constatou-se a possibilidade de um novo fator de mobilização da inteligência no trabalho: o medo. Segundo Dejours, até então se pensava que a mobilização subjetiva da inteligência e da engenhosidade no trabalho repousava essencialmente sobre a livre vontade dos trabalhadores. Hoje, a ameaça de demissão que paira sobre a maioria dos que trabalham acaba gerando o medo que os mobiliza a melhorar sua produção. Sob influência do medo, por exemplo, esses trabalhadores se mostram capazes de grande inventividade para melhorar a quantidade e a qualidade da sua produção, mesmo que para isso precisem "constranger" seus colegas, visando a conseguir posição mais favorável no processo seletivo de dispensas.

O medo é hoje um recurso amplamente utilizado como ameaça pela administração das empresas. Porém, esclarece esse autor, há limites para a escala do gerenciamento pela ameaça, já que depois de certo nível e tempo, o medo paralisa, pois "quebra o moral" do coletivo. Além disso, é imprevisível o prazo para os limites se revelarem, ao contrário do que prevêem as teorias clássicas da motivação, que consideram ilimitada a mobilização da inteligência pela gratificação e reconhecimento do trabalho bem-feito.

Na concepção de Dejours, existem realmente dificuldades na organização da produção; são inevitáveis as tensões; os resultados são conseguidos com dificuldade; é autêntico o sofrimento dos empregados estatutários e dos que trabalham em empregos precários, "mas o sistema funciona e parece mesmo poder funcionar duradouramente dessa 
maneira" (idem, p. 58). Ou seja, parece sinalizar esse autor vida longa para o regime flexível[29] do capital.

\section{Considerações finais}

A análise da situação mundial contemporânea ressalta expressiva e dramaticamente a intensidade da crise estrutural global do capitalismo. Ao contrário das crises anteriores, que foram parciais e localizáveis, parece que pela primeira se vê o capitalismo abalado em suas bases como sistema mundial. Contrastando com situações passadas, o caráter visivelmente global da crise sócio-econômica demanda soluções globais para os problemas do nosso tempo.

$\mathrm{Na}$ atual fase de desenvolvimento sócio-histórico, os problemas relacionados ao mundo do trabalho têm implicações globais, pois, embora de maneiras distintas, envolvem todos os sistemas sociais existentes. Tratando-se de uma fase de transição do fordismo para a acumulação flexível, as novas tecnologias e formas de organização flexível não se tornaram hegemônicas em todos os lugares, havendo, portanto, a convivência de uma produção fordista altamente eficiente, em alguns setores e regiões, e de sistemas de produção mais tradicionais, apoiados em relações de trabalho artesanais, paternalistas ou familiares. O crescimento destes últimos, até mesmo em países capitalistas avançados e, muitas vezes, em detrimento da maneira fordista de produção, significa uma mudança com sérias implicações, tanto na produção e apropriação de mais-valia, como na natureza e composição da classe trabalhadora global. E, também, nas condições de formação da consciência e da ação política. Nesse sentido, está mais do que nunca evidente a atualidade do conceito marxista de "transcendência da auto-alienação do trabalho", ou seja, não se pode mais conceber hoje como tarefa histórica mundial e imediata a conquista política do poder, mas em termos de alternativas estratégicas sócio-econômicas, com implicações globais de longo alcance.

Se na perspectiva de Marx o caráter social do trabalho se manifesta diretamente, sem a mediação alienante da divisão do trabalho, na realidade capitalista dos nossos dias, porém, a divisão do trabalho separa o homem das condições e poderes da vida, e faz com que estes o governem. A competitividade tornou-se uma arma na luta pela sobrevivência, individual, empresarial, entre países e num mesmo país. Nessa guerra "sem recurso às armas", os trabalhadores considerados velhos, que perderam a agilidade, e jovens "mal preparados" são alvo fácil de demissão, mas, também os tidos como aptos, se não corresponderem às exigências de maior produtividade, disponibilidade, disciplina e abnegação. Por outro lado, a precarização, que não é específica dos trabalhadores precários, tem grandes conseqüências sobre as relações e condutas dos que estão empregados, pela facilidade de substituição e demissão, graças às freqüentes infrações das leis trabalhistas e à flexibilização da organização e relações de trabalho. Essas, entre 
tantas outras, são causas de sofrimento no trabalho.

A flexibilidade ganhou hoje o espaço outrora destinado à rotina. Se esta se converteu numa conquista pessoal, no início do capitalismo industrial, ao converter-se para os trabalhadores numa "arena" onde podiam afirmar suas próprias exigências e seu poder, a flexibilidade e a mobilidade, contraditoriamente, transformaram-se em poderes de maior controle sobre a força de trabalho. Tal não surpreende, considerando que a acumulação flexível é uma forma de capitalismo, sendo, portanto, de se esperar a manutenção das condições necessárias do modo capitalista de produção. E esta dinâmica aponta a tendência, no atual momento, de acumulação flexível do capital, com uma "recombinação" de mais-valia absoluta e mais-valia relativa. Estas duas estratégias de obtenção de lucro, vêm a se configurar, por um lado, na intensificação do trabalho, com mais horas de trabalho e a redução geral das condições de vida pela erosão do salário real. Por outro lado, com a recorrência a novas formas organizacionais e tecnológicas, é posta em prática uma ação para gerar lucros temporários para firmas inovadoras e lucros mais generalizados com a redução dos custos de bens que definem o padrão de vida do trabalhador, e com isso gerando excedentes de força de trabalho.

A fase de acumulação flexível pode, portanto, assim ser concebida, exatamente pela origem e natureza da mais-valia produzida. E, como a questão da alienação está diretamente relacionada com a questão do produto excedente e da mais-valia, trata-se de entender como se produz a subjetividade nesse contexto do capitalismo "flexível". Para isso, mostra-se imperativo compreender, não apenas as causas do sofrimento no trabalho, mas também o sistema de poder que se oculta nas modernas formas de flexibilidade.

Considerado o caráter social do trabalho, que é a condição absoluta de uma sociedade, e que a divisão do trabalho expressa as condições de alienação, a questão que se coloca é como superar a alienante condição histórica da divisão do trabalho, frente à flexibilidade no mundo do trabalho e na produção das novas subjetividades. Trata-se, pois, de pensar a questão no âmbito da auto-realização e emancipação humana.

\section{Referências bibliográficas}

DEJOURS, Christophe. A banalização da injustiça social. Rio de Janeiro: FGV Editora, 1999.

HARVEY, David. Condição pós-moderna. São Paulo: Edições Loyola, 2002.

MARX, Karl. O Capital: crítica da economia política. São Paulo: Abril Cultural, 1983.

MÉSZÀROS, István. Marx: a teoria da alienação. Rio de Janeiro: Zahar Editores, 1981.

SENNETT, Richard. A corrosão do caráter. Rio de Janeiro: Editora Record, 1999. 
* Este trabalho apresenta parte do estudo preliminar desenvolvido pela autora com vistas a uma pesquisa sobre a formação e as condições de trabalho do professor das licenciaturas.

\section{** Doutoranda no PPFH/UERJ- Programa de Políticas Públicas e Formação Humana da Universidade do Estado do Rio de Janeiro. mariemi@terra.com.br.}

[1] Tomamos aqui a definição de Sennett (1999, p. 10) sobre o caráter: "traços pessoais a que damos valor em nós mesmos, e pelos quais buscamos que os outros nos valorizem".

[2] E Harvey acrescenta, "se, afinal, os trabalhadores estivessem convencidos de que os capitalistas podem incorporar práticas de trabalho mais flexíveis mesmo quando eles não o podem, a disposição de luta dos trabalhadores por certo será enfraquecida" (Harvey, 2005, p. 179).

[3] A propósito dessas questões: “As coordenações de mercado (freqüentemente do tipo subcontratação) se expandiram em prejuízo do planejamento corporativo direto no âmbito do sistema de produção e apropriação de mais valia. A natureza e a composição da classe trabalhadora global também se modificaram, o mesmo ocorrendo com as condições de formação de consciência e de ação política. A sindicalização e a 'política de esquerda' tradicional tornaram-se muito difíceis de manter diante de, por exemplo, sistemas de produção patriarcais (familiares) características do Sudeste Asiático ou de grupos imigrantes em Los Angeles, Nova Iorque e Londres. As relações de gênero também se tornaram muito mais complicadas, ao mesmo tempo que o recurso à força de trabalho feminina passou por ampla disseminação. Do mesmo modo, aumentou a base social de ideologias de empreendimentismo, paternalismo e privatismo" (idem, p. 179).

[4] Não é objetivo da presente exposição aprofundar tal análise, mas tão somente esboçar o delineamento dos pontos a serem posteriormente analisados com maior propriedade, quando da elaboração do capítulo primeiro da tese a que se reporta o presente texto.

[5] Conforme ressalta Harvey (2005, p. 170), na análise de Marx, não havia "uma maneira pela qual a combinação dessas três condições necessárias pudesse produzir um crescimento equilibrado e sem problemas; além de as tendências de crise do capitalismo apresentarem a tendência de produzir fases periódicas de superacumulação - definida como uma condição em que podem existir ao mesmo tempo capital ocioso e trabalho ocioso sem nenhum modo aparente de se unirem esses recursos para o atingimento de tarefas socialmente úteis. Uma condição generalizada de superacumulação seria indicada por capacidade produtiva ociosa, um excesso de mercadorias e de estoques, um excedente de capital-dinheiro (talvez mantido como entesouramento) e grande desemprego. As condições que prevaleciam nos anos 30 e que surgiram periodicamente desde 1973 têm de ser consideradas manifestações típicas da tendência de superacumulação".

[6] A primeira condição é que "uma taxa equilibrada de crescimento é essencial para a saúde de um sistema econômico capitalista, visto que só através do crescimento os lucros podem ser garantidos e a acumulação do capital, sustentada. Isso implica que o capitalismo tende preparar o terreno para uma expansão do produto e um crescimento em valores reais (e, eventualmente, atingi-los), pouco importam as conseqüências sócias, políticas, geopolíticas ou ecológicas. Na medida em que a virtude vem da necessidade, um dos pilares básicos da ideologia capitalista é que o crescimento é tanto inevitável como bom. A crise é definida, em conseqüência, como falta de crescimento" (idem, p.164).

[7] Isso não significa "que o trabalho se aproprie de pouco, mas que o crescimento sempre se baseia na diferença entre o que o trabalho obtém e aquilo que cria. Por isso, o controle do trabalho, na produção e no mercado, é vital para a perpetuação do capitalismo. O capitalismo está fundado, em suma, numa relação de classe entre capital e trabalho. Como o controle do trabalho é essencial para o lucro capitalista, a dinâmica da luta de classes pelo controle do trabalho e pelo salário de mercado é fundamental para a trajetória do desenvolvimento capitalista" (Harvey, idem, p. 166).

[8] Esse fato "decorre em parte das leis coercitivas, que impelem os capitalistas individuais a inovações em sua busca de 
lucro. Mas a mudança organizacional e tecnológica também tem papel-chave na modificação da dinâmica da luta de classes, movida por ambos os lados, no domínio dos mercados de trabalho e do controle do trabalho. Além disso, se o controle do trabalho é essencial para a produção de lucros e se torna uma questão mais ampla do ponto de vista do modo de regulamentação, a inovação organizacional e tecnológica no sistema regulatório (como o aparelho do estado, os sistemas políticos de incorporação e representação etc.) se torna crucial para a perpetuação do capitalismo. Deriva em parte dessa necessidade a ideologia de que o "progresso" é tanto inevitável como bom“ (idem, ibidem).

[9] Segundo Harvey, há muitos exemplos e abundantes provas da desvalorização como resposta à superacumulação a partir de 1973, mas "a desvalorização tem um alto preço político e atinge amplos segmentos da classe capitalista, da classe trabalhadora e das várias outras classes sociais que formam a complexa sociedade capitalista moderna”. Contudo, argumenta o autor, "a desvalorização controlada através de políticas deflacionárias administradas é uma opção muito importante e de modo algum incomum para lidar com a supercumulação" (idem, p. 170).

[10] Harvey (idem, ibidem) avalia que "a virtude do regime fordista-keynesiano, foi, com efeito, a possibilidade de criação de um equilíbrio de forças, mesmo tênue, através do qual os mecanismos que causavam o problema da superacumulação (o ritmo da mudança tecnológica e organizacional e a luta pelo controle do trabalho) pudessem ser mantidos sob suficiente controle para se garantir um crescimento equilibrado".

\section{[11] Sobre esse ponto, ver Harvey (2005, p. 171-173).}

[12] Mesmo os novos sistemas de produção tenderam a se transferir, uma vez padronizados, dos seus centros inovadores para localidades terceiro-mundistas (a transferência da Atari, em 1984, do Vale do Silício para o Sudeste Asiático, com sua força de trabalho de baixa remuneração, é um caso exemplar) (Harvey, 2005, p. 174).

[13] Para o autor, o resultado desse processo é um tipo de estrutura de mercado de trabalho conforme o detalhado no Flexible Patterns of Work (1986, apud Harvey, 2005, p. 143).

[14] Essas formas mais antigas, são "com freqüência dominadas por novos grupos de imigrantes em grandes cidades, como filipinos, sulcoreanos, vietnamitas e naturais de Taiwan em Los Angeles, ou indianos e nativos de Bangladesh no leste de Londres" (Harvey, idem, p. 145).

[15] Conforme ressalta Harvey, o 'acesso à informação, bem como o seu controle, aliados a uma forte capacidade de análise instantânea de dados, tornaram-se essenciais à coordenação centralizada de interesses corporativos descentralizados. A capacidade de resposta instantânea a variações das taxas de câmbio, mudanças das moedas e dos gostos e iniciativas dos competidores tem hoje um caráter mais crucial para a sobrevivência corporativa do que teve sobre o fordismo" (idem, p.151).

[16] "Boa parte da fluidez, da instabilidade e do frenesi pode ser atribuída diretamente ao aumento dessa capacidade de dirigir os fluxos de capital para lá e para cá de maneiras que quase parecem desprezar as restrições de tempo e de espaço que costumam ter efeito sobre as atividades materiais de produção e consumo" (idem, p. 155).

[17] Esse era o sentido original de job (hoje: serviço, emprego), no inglês do século XIV (Sennett, 1999, p. 91).

[18] Em meados da década de 1990, por exemplo, tornou-se claro para muitos líderes empresariais que "só na vida de fantasia e muitíssimo bem paga dos consultores pode uma grande organização definir um novo plano de negócios, enxugar-se e 'replanejar-se' à perfeição, e depois tocar em frente o novo projeto" (Sennett, 1999, p. 57).

[19] Segundo Sennett (1999, p. 59), "alguns economistas têm mesmo afirmado que, quando se somam todos os custos do trabalho computadorizado, a tecnologia mostra de fato um déficit de produtividade." Argumanta esse autor que "ineficiência ou desorganização não significam, porém, que não há sentido na prática da mudança aguda, demolidora" e que "na operação dos mercados modernos, a demolição de organizações se tornou lucrativa",. Entende também que, 
“embora possa não ser justificável em termos de produtividade, os retornos a curto prazo para os acionistas proporcionam um forte incentivo aos poderes do caos disfarçados pela palavra "reengenharia", que parece convincente". Observa, também, que empresas perfeitamente viáveis "são estripadas ou abandonadas, empregados capazes ficam à deriva, em vez de ser recompensados, simplesmente porque a organização deve provar ao mercado que pode mudar".

[20] A “desagregação vertical” dá aos membros de uma ilha empresarial múltiplas tarefas a cumprir (Sennett, 1999, p. 56).

[21] Eliminar camadas (“delayering”) é "a prática específica de oferecer a um menor número de administradores controle sobre um maior número de subordinados” (idem, ibidem).

[22] Segundo Sennett (1999, p. 67), nas economias desenvolvidas do mundo em 1990, quase 50 por cento da força de trabalho profissional liberal e técnica já eram de mulheres, a maioria empregada em tempo integral, porém, essas trabalhadoras precisavam "de horas de trabalho mais flexíveis; em todas as classes, muitas delas são empregadas de meio período e mães em período integral”.

[23] O flexitempo é bem diferente da forma de organizar o trabalho, até então conhecida: "não é como o calendário de folgas, em que os trabalhadores sabem o que esperar; tampouco é comparável com o simples total de horas semanais de trabalho que uma empresa pode estabelecer para seus empregados de nível inferior" (idem).

[24] Sennett (1999, p. 43) destaca que Marx acrescenta à descrição da rotina da fábrica de alfinetes de Smith "o contraste com práticas mais antigas, como o sistema alemão de Tagwerk, em que o trabalhador era pago por dia; nessa prática, o trabalhador podia adaptar-se às condições de seu ambiente, trabalhando diferente quando chovia ou fazia sol, ou organizando tarefas para levar em conta a entrega dos suprimentos; havia ritmo nesse trabalho, porque o trabalhador estava no controle".

[25] A fábrica de Highland Park, da The Ford Motor Company.

[26] Os outros 15 por cento eram limpadores e faxineiros não qualificados e os artesãos e técnicos haviam caído para 15 por cento (Sennett, 1999).

[27] A metáfora utilizada por Smith, não se aplicava à imensa jaula em que se transformou a Willow Run, fábrica de automóveis da General Motors, em Michigan.

[28] Neste tópico, recorro à análise de Dejours (1999), pelo que contribui nesta discussão sobre os efeitos do mundo do trabalho, particularmente sob os aportes psicológicos e éticos, na formação das subjetividades atuais.

[29] Utilizo aqui a palavra regime no sentido que lhe dá Sennett (1999, p. 63): "sugere os termos de poder nos quais se permite que operem os mercados e a produção". 